\title{
Kayısı Hasatında Bir El Silkeleyicinin Bazı Parametrelerinin Belirlenmesi
}

\author{
Metin GÜNER'
}

Ibrahim GEZER ${ }^{2}$

\author{
Geliş Tarihi : $12,07.2000$
}

\begin{abstract}
Ozet: Bu araştımada el silkeleyicinin kayısı hasatındaki iș başarısı $(\mathrm{kg} / \mathrm{h}$ ve ağaç/h), yakıt toketimi (1/h) ve hasal etkinilğl (\%) gibi bazı parametrelerí belirlenmiștir. Elde edilen sonuçlar klasik hasat yôntemiyle Karșilaștirilmıştır. Denemeler 3 tekerrírí olarak yapilmış ve her tekerrurde $1 \mathrm{~h}$ súreyie hasat gerçekleştirimiş̧tir. Hern el silkeleyici ve hem de klasik yontemde hasat aynı kişi yapmıştır. El silkeleyicinin genliği $60 \mathrm{~mm}$ ve frekansı $20-23 \mathrm{~Hz}$ 'dir. Yan dallara bağlanan el silkeleyici 2 defa aralıkłı ve $4 \mathrm{~s}$ süreyle tam gazda çalıștirılmıștı. Denemeler sira arası 10m olan ve 8.12 yaşlarındaki kayısı ağaçlarında yürotüımúş̧ur. Araştırma sonucunda el silkeleyici iş başarısı bir saatte hasat edilen kayısı olarak \% 38,6 ve ağaç sayısı olarak da $\% 48,48$ artırdı̆ıı bulunmuștur, Yakıt tóketimi ortalama $1,41 / \mathrm{h}$, hasat etkinliği ise $\% 99,7$ olarak belirlenmiştir.
\end{abstract}

Anahtar Kelimeler; Kayısi hasatı, el silkeleyicĩ, is başarısi, yakıt tôketimi, hasat etkinilgi

\section{Determination of Some Parameters of Hand Shaker in Apricot Harvesting}

\begin{abstract}
: in this research some parameters of hand shaker such as rate of work $(\mathrm{kg} / \mathrm{h}$ and tree/h), fuel consumption $(1 / h)$ and harvesting rate $(\%)$ were determined. The results were compared with conventional apricot harvesting. The lests are carried out three replications and apricots are harvested a period of $1 \mathrm{~h}$ in the each replication. Both conventional harvesting and mechanical harvesting were done by the same person. Hand shaker has an amplitude of $60 \mathrm{~mm}$ and a frequency of $20-23 \mathrm{~Hz}$. The hand shaker fastened to the side branches are operated at two intervals of $4 \mathrm{~s}$ on the maximum engine speed. The trees in the tests are about 8-12 old years and have a row width of $10 \mathrm{~m}$. At the and of the tests it was found that the hand shaker increased the rate of work $38,6 \%$ as $\mathrm{kg} / \mathrm{h}$ and $48,48 \%$ as tree/h. The power consumption and the harvesting rate are determined as $1,41 / \mathrm{h}$ and $99,7 \%$ respectively.
\end{abstract}

Key Words; Apricot harvesting, hand shaker, rate of work, fuel consumption, harvest efficient

\section{Giriş}

Meyve ve sebzelerin makinalı hasatında koparma, kontrol, seçim ve tașıma işlemlerinin tümü ya da bir kısmı makinayla yapilmaktadır. Koparma işleminde, enerji uygulanarak meyve ve sebzeler dalindan kesilerek, çekilerek, bakalerek yada döndarölerek hasat edilmektedir. Enerii uygulaması elle hasatta ve robotik uygulamalarda olduğu gíbi doğrudan meyve ve sebzeye ya da hasat makinalarındaki gibi dala ya da góvdeye yapılmaktadir. Tutma platformlan óranterin zedelenme kontrolana sağlamaktadır. Seçim işleminde hedef ürünün olgun, yeteri böyüklókte olup olmamasina bakilır. Elle ve robotik uygulamalarda seçim işlemi kolaylikla yapılabilirken diğer hasat yöntemlerinde seçme şansı çok azdir. Hasat edilen meyve ve sebzeler ya yığma ya da kasalarla taşınmaktadır. Meyve ve sebze çeşitlerinin çok fazla olmasindan dolayi hasat makinalarinin siniflandirilması ya da birkaç başlik altında toplanması zordur. Hasat yöntem ve makinalari bitkinin hasat edilecek kısminin toprak yüzeyíne gôre konumuna bağlı olarak sınıflandırılabilir. Buna göre hasat makinaları havuç, şeker pancan, soğan, yerfıstığı, patates, turp, şalgam gibi kókö sebzelerin hasatinda kullanilan makinalar, lasulye, lahana, kereviz, salatalık, marul, bezelye, cilek, domates, enginar, kuşkonmaz, brokoli, karnabahar, biber, Ispanak gibí yüzey sebzelerinin hasatında kullanilan makinalar, ozom, ananas, siyah ağaç çileği, kahve, frenk uzümu, kivi gibi çalı ve asma tip meyvelerin hasatında kullanilan makinalar ve son olarak da badem, hurma, incir, fındik, zeytin, erik, şeftali, kayısı, ceviz gibi ağaç meyvelerinin hasatında kullanilan makinalar olarak incelenebilir. (Srivostava ve ark. 1993)

Ag̈aç meyvelerinin hasatında kullanilan makinalar Keçecioğlu (1975) tarafindan el silkeleyiciler, kablolú silkeleyiciler, darbeli silkeleyiciler, eksantrik silkeleyiciler, ve atalet kuvvet tipli silkeleyiciler olarak sınıflandırımıştır, Ağaç meyvelerinin hasatinda ya dal ya da govde silkelenmektedir. El silkeleyicilerle aḡaç gövdeden ya da ana dallardan silkelenmeyip, hasat için küçăk çapli yan dallar kullanilmaktadit. Pnömatik ya da krank biyel mekanizmasiyla elde edilen titreşim hareketi bir çubuk yardimıyla yan dallara iletilmekte kısa araliklarla titreşim uygulanarak hasat gerçekleştirilmektedir Silkeleyici motoru üzerinde olup elektrik veya termik motortu olabilmektedir. Titreşimin dala zarar vermemesi için çubugunn dala temas eden ucuna kauçuk yerleștirilmektedir.

Meyve ve sebzelerin hasatınin makinayla yapilması için yapılan çalışmalar yabancı literatûfler de çok eskilere dayanırken, Türkiye'de yapilan çalışmalar ancak son yıllarda Ivme kazanmıştır. Keçecloğlu (1975), atalet kuwvet tipll bir silkeyici imal ederek zeytin hasatında kullanmıştır. Fridley ve Adrian (1960), ağaç meyvelerinin hasatında frekans, genlik meyvenin kopması. güç, kuvvet arasindakì ilişkileri incelemiştir. Lamouria ve ark, (1961), kablolu ve eksantrik silkeleyici ile geliştirdikleri el kumandalı ve traktörle çekilir iki tip tutma platformuyla zeytin, şeftali ve

\footnotetext{
'Ankara Univ. Ziraat Fak. Tarım Makinaları Bölumü-Ankaia

${ }^{2}$ Inönä Univ Malatya Meslek roksekakulu-Malatya
} 
ammut hasatı yapmışlardır. Markwardt ve ark. (1964), kirazin mekanik hasatıyla ilgili çalişmalarda bulunmuşlar, tutma platformu geliştirerek hasat etkileyen parametreleri incelemislardir. Adrian ve Fridley (1965), atalet kuwvet tipli bir silkeleyicinin temel titreşim katakteristiklerini vemișlerdir. Diener ve ark (1965), elma hasatinda kullanilmak uzere mobil, krank mekanizmali bir silkeleyicı imal etmișlerdir. Bu silkeleyici hareketini değişken hizi motordan almaktacdir. Silkeleyicıyi bodur elma ağaçlarınde kullanmışlar teorik ye deneysel çalışma yapmişlardıt. Schertz ve Brown (1968), turunçgll hasat makinalarınin tasarimindaki bazi temel yaklaşimlan incelemişlerdir. Lenker ve Hedden (1968), portakalın makinalı hasatinda dal boyutlarinin, frekans ve genliğinin, titreșimin dazgüniogüüun etkisi araştırmışlardır. Whitney ve Patterson (1972) lle Chesson (1974), turunçgilin mekanik hasatı azerinde çalişmişlardif. Fridley ve ark. (1973), zeytinin mekanik hasatı adlı araștımalarında bir silkeleyici tasariminda; titreşimin kontrola, uygun frekans ve genlik, mobil olma ve kolayca aḡaca bağlanabilme ve ekipmanın doğru kullanimi için operatörōn eğitimli olması faktörlerinin göz onünde bulundurulması gerektiğini vurgulamişlardic Parameswarakumar ve Gupta (1991), atalet kuvvet tipli bir silkeleyici geliş̧tirerek Hint kirazı (mango) hasatında kullanmışlardır. Beyhan (1996) eksantrik tipli bir silkeleyicinin findığin mekanik hasatinda kullanabilme olanaklarını araştırmıştıc. Findığın tutunma kuvvetini blçmos ve hasat edilen meyve yuzdesl ile olgunlaşma arasinda ilişki kurmusstur. Findik meyvelerinin dôșârolmesinde silkeleyici parametresi olarak $15 \mathrm{~Hz}$ frekans, $35 \mathrm{~mm}$ genlik ve 5 sanlye süfe değerleri uygün buiunmuştur. Polat ve Olger (2000), antepfistig̈ının mekanik hasatında oc farkli silkeleyici kullanmışlar, meyve tutunma kuvvetinin meyve ağirliğina oranini, dal yaylanma katsayısini ve hasat etkinliğini belirlemişlerdir. Makinaların hasat etkinliğini belitleme de hasat edilen meyve toplam (dalda kalan ve hasat edilen) meyve ağırliğina bolünerek bulunmuştur, Ozarslan ve Saraçoğlu (2000), geçmișten gunamuze gelişim surecinde bazi zeytin hasat makinalan, tutma platformiari ve toplama makinalari hakkinda bilgi vermişlerdir. Pirlak ve Guleryüz (2000), meyvecilikte kullanilan hasat yontemleri, meyvelerin mekanik hasati konusunda açılamalar yapmışlardir.

Bü calișmamizda bir el silkeleyicinin kayısi hasatindaki bazı periormans karakteristikleri betirlenmeye çalişilmiștır. El silkeleyici Malatya ili kayisi bahçelerinde yapilmiștir, Malatya'da gerellikle kayisi uretimi kurutma amacıyla yapilmaktadir. Bu nedenle kayisinin mekanik hasati da bu amaca yönelik olmuştur.

\section{Materyal ve Vöntem}

Araştımada tek silindirfi, hava soğutmalı, jki zamani bir el silkeleyici kullanilmiștır (Şekil 1). Silkeleyici motorunun guco $1,6 \mathrm{~kW}$ toplam uzuniugu $2620 \mathrm{~mm}$ toplam genişliği $320 \mathrm{~mm}$, yüksekiği $270 \mathrm{~mm}$, ağırliğ 120 N'dur. Motorun yúksoz koșullarinda silkeleyicinin strodu 60 $\mathrm{mm}$ ve frekansi $2 \mathrm{D}-23 \mathrm{~Hz}$ arasinda degissmektedir. Silkeleyicr, motor, govde ve titreșim çubuğu olmak azere :3 bolarnden oluşmaktadir. Motor bolamunde silindir, yakit deposu ve paliștimma dazeni, govde bolümünde titresimi, kullanan kişiye jetilmesine engel olan silkeleyicinin taşınmasını saglayan aski, kumanda kollarini taşiyan tutamak, amortisörlo o̊n tutma kolu bulunmaktadir.
Titreşim çubuğunun ucunda ağ̀ız açıklığı $42 \mathrm{~mm}$ olan bî́ kanca vardir. Motordan alinan hareket eksantrik mekanizmasiyla titreșim çubuğuna iletilmektedir. Titreşim çubuğu gaz kumanda kolunun durumuna gôre 1200 fle 1400 d/d devirle ileri-geri hareket etmektedir. Silkeleyici. aski takımı yardimiyla sirta esilmakta ve motor çaliștirma duzeni ip sarili geri donuşlo yaylı tip olmaktadır. Titreşim çubuğundaki kanca $42 \mathrm{~mm}$ ve daha kuçuk captaki dallara takilmakta ve gaz verilerek hasata başlanmaktadır.

Araștırmada; 1 dala, 2 defa aralıklı ve 4 s süreyle tam gazda titreşim verilerek hasat yapilmiștır. Silkeleyicinin yakıt tüketimi, iş başarısı ve hasat etkinigi belirlenimiştir. Is bașarısi klasik yontemle karşılaştırılmıştır. Yakit tüketiminin belifenmesinde ekleme (tamamlama) yontemi kullanilmıștir. Silkeleyici tam dolu yakit deposuyla birer saatlik sürelerle hasatta kullanilmis ve her bir saatteki yakit toketimi depoya yakt ekleyerek bulunmuştur. Is başarisinin bellftenmesinde el silkeleyic ile bir saatlik surelerle yan dallar hasat edilmiș, silkeleyicinin hasat edemediği ortadakt dallar sirikła vurularak ya da elle silkelenerek hasat tamamianmiştır. Klasik yontemdeki hasatta kayısilar sirikla ve elle silkelenmiştir. Is başarısı, hasat edilen kayıs tartilarak $\mathrm{kg} / \mathrm{h}$ ve hasat edilen ağaç sayllarak ağaçh olarak bulunmuştur. Silkeleyici ile hasatta ve klasik yöntemdeki hasatta $B 2 \mathrm{~kg}$ ağirliginda ve $1,75 \mathrm{~m}$ boyunda aynı kiși çalıșinıştir. Iş başarısi ve yakit toketimi olçumlen 3 er tekrarii olarak yapilmıștır. Ağacin gővde çap), govde yoksekliği, taç çapi, ağaç yoksakliği seritmetreyle olçolmuştür. Agaçlarin sira arasi $10 \mathrm{~m}$ sira Uzzeri $\mathrm{B} \mathrm{m}$ Givarindadir. Yaşları 8 ila 12 arasında değişmaktedir

Hasat etkinliḡini belirlemede bir dala 2 defa va 4 s araliki) olarak silkeleyiciyle titreșim verilmiş, hasat edilen kayrei ağıriğl $\left\langle W_{1}, \mathrm{~kg}\right.$ ), dalda kalan $\left(\mathrm{W}_{2}, \mathrm{~kg}\right)$ ve hasat edilen kayisi toplamiria $\left(W_{1}+W_{2}\right)$ boilanerek buiunmugstur.

$$
\text { Hasat EnkinLig }(\%)=\frac{W_{1}}{\left(W_{1}+W_{2}\right)} \times 100
$$

Kayısi çeşidi olarak Hacihalilog̀lu alinmiştır. Hacihatiloglu kayisısının hasat sirasindaki suda çöonebelir kuru madde (SÇKM) orani Atago marka olçme aralıăl \%0-32 olan el refraktometresi, tutunma kuvveti (kopma direnci) $10 \mathrm{~N}$ olçme kapasitell ve 0,1 $\mathrm{N}$ bolontolo el dinamometresi, meyve eti sertigi FT Or1, $0-5 \mathrm{~kg} / \mathrm{cm}^{2} \mathrm{lik}$ el penetrometresl ve meyve kabuk rengi Minolta Chrometer Cr 200 tip renk analiz cihazi ile belirlenmisstir. Denemeler Temmuz ayının lik haftası yapilmıştir.

\section{Bulgular ve Tartişma}

El silkeleyici ve klasik yöntemle yapilan kayısı hasatında góvde çapi, gớvde yüksekliḡi, tą̣ çapi, agạç yoksekliği, is başarasi ( $\mathrm{kg} / \mathrm{h}$, ag̣aç/h), yakit tôketimi (1/h) ve hasat etkınliği (\%) değerleri çizelge 1'de verilmiştir. Denemeye alınan Hacihaliloğlu kayisi çeșidinin suda çozonebilir kuru madde oranı (SCCKM) \%27,8, tutunma kurveti (kopma direnci) $5,98 \mathrm{~N}$, meyve eti sertliği 88260 $\mathrm{Pa}_{\mathrm{a}}$, rengi turuncu olarak saptanmıştir. Çizelge 1 'de verilen degerlerden is başarisinin aritmetik ortalamasi el silkeleyicide $559 \mathrm{~kg} / \mathrm{h}$ ve 9,8 ăgac/h'tır. Klasik yöntemdeki iş başanı değerlerinin ortalaması ise $403,3 \mathrm{~kg} / \mathrm{h}$ ve 6,6 . ağac/h olmuștur 

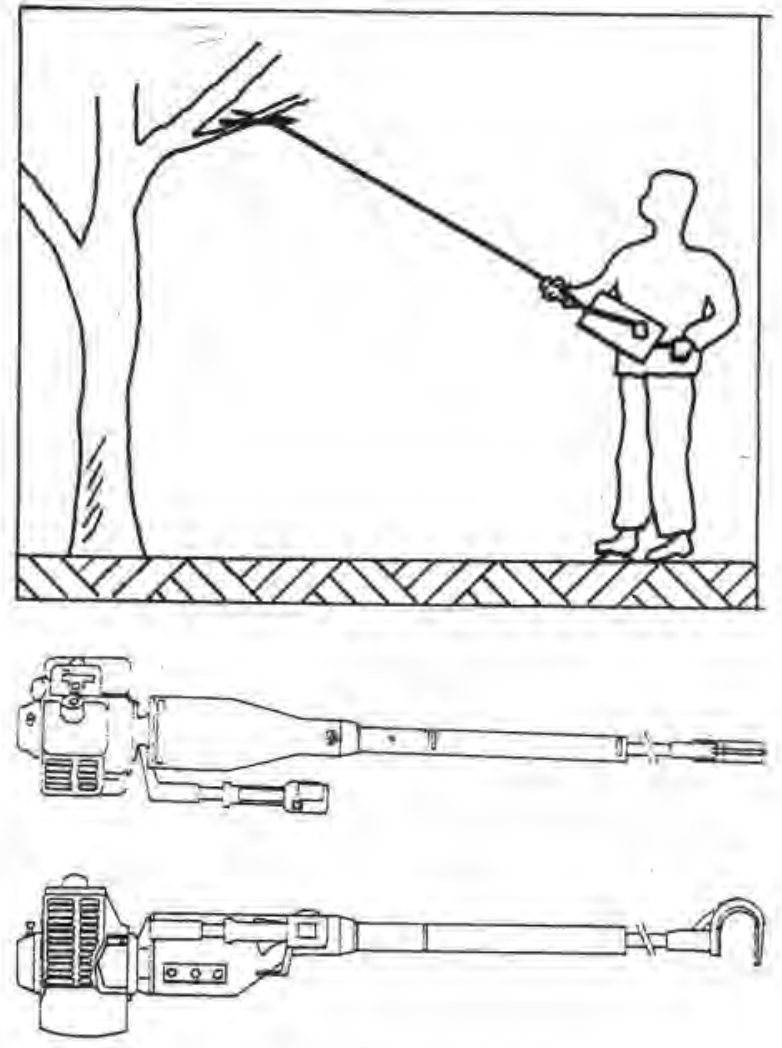

Şekil 1. El Silkeleyici ve ağaçta kullanımı
Buna göre el silkeleyicisinin iş başarısı; $\mathrm{kg} / \mathrm{h}$ olarak ((559$403,3) / 403,3) \cdot 100=\% 38,6$ ağaç/h olarak $((9,8-$ $6,6) / 6,6) \cdot 100=\% 48,48$ daha fazladır. Iș başarısı ağacın meyve verimliliğine oldukça bağlıdır. Bu nedenle deneme ağaçlarına bağlı olarak farklı sonuçlara ulaşılabilir. Ancak kesin olan sonuç el silkeleyicinin iş başarışını artırdığıdır. Nitekim Kettner (1966) el silkeleyicinin iş başarısını \% 50 artırdığını bildirmektedir (Keçecioğlu 1975).

El silkeleyicinin yakıt túketimi ortalama $1.4 \mathrm{1} / \mathrm{h}$ bulunmuștur. Tarım ve Köyişleri Bakanlığı Tarım Alet ve Makinaları Test Merkezi Müdürlüğünde yapılan bir denemede el silkeleyici yakıt tăketimi 1,2 1/h olarak bildirilmektedir (Anonim 1999). Silkeleyiciyle 2 defa 4 'er saniye süreyle yapilan hasatta hemen hemen tăm kayısılar hasat edilmiş ortalama hasat etkinliği \%99,7 bulunmuștur. Klasik yöntem de ağaç Qzerinde kayısı kalmayıncaya kadar hasata devam edildiğinden hasat etkinliği \% 100 olmuştur.

\section{Sonuç}

El silkeleyīcinin kayısı hasatında kullanılması sonucunda, el silkeleyicinin özellikle yan dalların hasatında etkili olduğu görülmaştür. İs başarısını $\mathrm{kg} / \mathrm{h}$ olarak $\% 38,6$, ağaç/h olarak $\% 48,48$ artırmaktadır. Yakıt toketimi $1,4 \mathrm{l} / \mathrm{h}$ ve hasat etkinliği $\% 99,7$ olarak saptanmıştır. Kullanılan el silkeleyicisinin geliştirilmesine yönelik olarak titreşim çubuğunun biraz daha uzun olması ve $42 \mathrm{~mm}$ 'lik kancanın sapan gibi çatalli yapilması onerileri verilebilir.

Çizelge 1. El silkeleyici deneme sonuçları

\begin{tabular}{|c|c|c|c|c|c|c|c|c|c|}
\hline \multirow[b]{2}{*}{ Hasat yöntemi } & \multirow[b]{2}{*}{ Deneme no } & \multirow[b]{2}{*}{$\begin{array}{c}\text { Gövde } \\
\text { çapı } \\
(\mathrm{mm})\end{array}$} & \multirow[b]{2}{*}{$\begin{array}{c}\text { Gövde } \\
\text { yäksekliăi } \\
\text { (mm) }\end{array}$} & \multirow[b]{2}{*}{$\begin{array}{c}\text { Taç çapı } \\
\text { (mm) }\end{array}$} & \multirow[b]{2}{*}{$\begin{array}{l}\text { Ağaç } \\
\text { yüksekliği } \\
\text { (mm) }\end{array}$} & \multicolumn{2}{|c|}{ Iş başarısı } & \multirow[b]{2}{*}{$\begin{array}{c}\text { Yakit } \\
\text { tukketimi } \\
(1 / h)\end{array}$} & \multirow[b]{2}{*}{$\begin{array}{c}\text { Hasat } \\
\text { etkinligi (\%) }\end{array}$} \\
\hline & & & & & & $\left(\frac{\mathrm{kg}}{h}\right)$ & $\left(\frac{a g a c}{h}\right)$ & & \\
\hline \multirow{6}{*}{ El silkeleyiciyle hasat } & 1 & 220,00 & 1500,00 & 3500,00 & 5000,00 & 570,00 & 10,00 & 1,80 & 100,00 \\
\hline & $\pi$ & 260,00 & 1500,00 & 7000,00 & 6000,00 & 497,00 & 8,60 & 1,30 & 99,00 \\
\hline & III & 250,00 & 1400,00 & 5600,00 & 4650,00 & 610,00 & 10,80 & 1,10 & 100,00 \\
\hline & $\overline{\bar{x}}$ & 243,33 & 1466,66 & 5366,66 & 5216,66 & 559,00 & 9,80 & 1,40 & 99,70 \\
\hline & $\pm S$ & 20,80 & 57,78 & 1761,33 & 700,60 & 57,24 & 1,11 & 0,36 & 0,58 \\
\hline & CV (\%) & 8,55 & 3,94 & 32,82 & 13,43 & 10,24 & 11,36 & 25,75 & 0,58 \\
\hline \multirow{6}{*}{ Klasik yöntemli hasat } & 1 & 220,00 & 1300,00 & 4050,00 & 6350,00 & 400,00 & 6,70 & - & 100,00 \\
\hline & II & 210,00 & 1450,00 & 4270,00 & 4900,00 & 370,00 & 6,00 & - & 100,00 \\
\hline & III & 245,00 & 1560,00 & 5100,00 & 3900,00 & 440,00 & 7,10 & - & 100,00 \\
\hline & $\overline{\mathrm{x}}$ & 225,00 & 1436,66 & 4473,33 & 5050,00 & 403,30 & 6,60 & - & - \\
\hline & $\pm S$ & 18,02 & 130,44 & 553,80 & 1231,69 & 35,13 & 0,56 & - & - \\
\hline & CV (\%) & 8,01 & 9,08 & 12,38 & 24,39 & 8,71 & 8,44 & - & $=$ \\
\hline
\end{tabular}

$\overline{\mathrm{X}}$ : Aritmetik ortalama, $\pm \mathrm{S}$ : Standart sapma, $\mathrm{CV}(\%)$ : Varyasyon katsayıs।

\section{Kaynaklar.}

Adrian, P. A. ve R. B. Fridley. 1965. Dynamics and Design Criteria of inertia-Type Tree Shakers. TRANSACTIONS of the ASAE, 12-14.

Anonim, 1999. Mapaș Master Block 2000 Süper Ağaç Silkeleme Makinası Deney Raporu, T.C. Tarım ve Köyişleri Bakanlığı Tarım Alet ve Makinaları Test Merkezi Müdúrıŭgü, $8 \mathrm{~s}$, Ankara.
Beyhan, M. A. 1996. Fındığın Mekanik Hasatında Eksantrik Tipli Dal Silkeleyicinin Kullanılabilma Olanağının Belirlenmesi. Ondokuz Mayıs Üniversitesi Ziraat Fakültesi Findık ve Diğer Sert Kabuklu Meyveler Sempozyumu, 212-225, Samsun.

Chesson, J. H. 1974. Parameters Affecting Selective Shake Harvest of Citrus. TRANSACTIONS of the ASAE, 1085 . 1087. 
Diener, R. G., N. N. Mohsein and B. L. Jenks, 1965. Vibration Charaçteristics of Trellis-Trained Apple Trees With Reference to Fruit Detachment. TRANSACTIONS of the ASAE, 20-24.

Fridley, R. B. and P. A. Adrian. 1960. Some Aspects of Vibratory Fruit Harvesting. Agricultural Engineering, 28-31.

Fridley, R. B., J. Mehlschau, H. T. Hartmann and S. H. Logan, 1973. Mechanical Harvesting of Olives. TRANSACTIONS of the ASAE, 58-61.

Keçecioğlu, G. 1975. Atalet Kuvvet Tipli Sarsıcı ile Zeytin Hasatı Imkanları Üzerinde Bir Araştırma E.Ü.Z.F. Yayınları No: 288,52 s. Bornova, lzmir.

Kettner, $\mathrm{H}, 1966$. Mechanische Obsternte mit einem hadgefuhrten Vibrations-Geraet.Der Erwerbsobstbau 8, Heft 6.

Lamouria, L. H., H. T. Hartmann,. R. W. Harris and C.R. Kaupke, 1961. Mechanical Harvesting of Olives, Peaches and Pears. TRANSACTION of the ASAE, 12-14.

Lenker, D. H. and S. L. Hedden, 1968. Optimum Shaking Action for Citrus Fruit Harvesting. TRANSACTIONS of the ASAE, 347-349.

Markwardt, E. D., R. N. Guest, J. C. Cain and R.L. Labelle, 1964 Mechanical Cherry Harvesting. TRANSACTIONS of the ASAE, 70-74.
Özarslan, C. ve T. Saraçoğlu. 2000. Zeytin Hasat Mekanizasyonunda Gelişmeler. Tarımsal Mekanizasyon 19. Ulusal Kongresi 1-2 Haziran. 259-264, Erzurum.

Parameswarakumar, M. and C. P. Gupta. 1991. Design Parameters for Vibratory Mango Harvesting System. TRANSACTIONS of the ASAE, 14-20.

Pırlak, L. ve M. Güleryŭz, 2000. Meyve Türlerinin Mekanik Yolla Hasatı. Tarımsal Mekanizasyon 19. Ulusal Kongresi 1-2 Haziran. 253-258, Erzurum.

Polat, $R$, ve P. Ülger, 2000. Antepfıstığının Mekanik Hasat Olanaklarının Belirlenmesi Üzerine Bir Araştırma. Tarımsal Mekanizasyon 19. Ulusal Kongresi. 1-2 Haziran, 265-270, Erzurum.

Schetz, C. E. and G. K. Brown, 1968. Basic Considerations in Mechanizing Citrus Harvest. TRANSACTIONS of the ASAE, 343-346.

Srivostava A. K., C. E. Goering, and R.P. Rohrbach, 1993. Engineering Principles of Agricultural Machines. ASAE Text book Number 6, 445-501.

Whitney, J. D. and J. M. Patterson, 1972. Development of a Citrus Removal Device Using Oscillating Forced Air. TRANSACTIONS of the ASAE, 849-855. 